\title{
ATENOLOL MICROPARTICLES BY TWO-FACTOR TWO-LEVEL CENTRAL COMPOSITE DESIGN
}

\author{
ARTI SHARMA*, SUNIL K BATRA \\ Department of Pharmaceutics, Hindu College of Pharmacy, Sonipat, Haryana, India. Email: artish1114@gmail.com
}

Received: 23 December 2019, Revised and Accepted: 18 January 2020

\begin{abstract}
Objective: The objective of this research was to formulation, optimization, and evaluation of gastric-mucoadhesive microparticles which contains selective $\beta 1$ receptor antagonist atenolol.

Methods: The following chemicals were used, atenolol (Gangwal Chemicals Pvt. Ltd., Mumbai), ethyl cellulose (EC) (Loba Chemie Pvt. Ltd., Mumbai), Carbopol 940 (Loba Chemie Pvt. Ltd., Mumbai), liquid paraffin (Arora Pharmaceuticals Pvt. Ltd., New Delhi), and Span 80 (Central Drug House (P) Ltd., New Delhi). Microparticles were prepared by the emulsification solvent evaporation technique using polymers of Carbomer 934p (CP) and EC. Disc formulations were prepared by direct compression technique from microparticles. Microparticles of combined polymers were designed according to $2^{2}$ factorial central composite design (CCD), taking EC concentration and surfactant concentration as the independent variables. A total of 13 batches were prepared. The dependent variables were percentage of $\%$ drug released and \% entrapment efficiency.
\end{abstract}

Results and Discussion: All evaluation tests were done for the prepared 13 formulations, such as percentage entrapment efficiency, percentage drug release, swelling index, percentage yield, and particle size analysis. The entrapment efficiency of optimized formulation was found to be $72.02 \%$. The entrapment efficiency increases with increase in EC concentration and stirring speed. Optimized formulation was further subjected to study of drug release kinetics based on the R2 value; it was observed that Korsmeyer Peppas release kinetic model was found to be best suited for formulation of atenolol with EC: carbopol 934 by solvent evaporation method.

Conclusion: The optimized formulation of microparticles containing atenolol was found to be homogeneous, good appearance and had well flow properties and better release kinetics.

Keywords: Selective $\beta 1$ receptor antagonist, Entrapment efficiency, Design-Expert, Solvent evaporation, Variables, Central composite design.

(C) 2020 The Authors. Published by Innovare Academic Sciences Pvt Ltd. This is an open access article under the CC BY license (http://creativecommons. org/licenses/by/4. 0/) DOI: http://dx.doi.org/10.22159/ajpcr.2020.v13i4.36467

\section{INTRODUCTION}

It is evident from the recent scientific and patient literature that an increased interest in novel dosage forms that are retained in stomach for a prolonged and predictable period of time exists today in academic and industrial research groups. One of the most feasible approaches for achieving a prolonged and predictable drug delivery in the gastrointestinal tract (GIT) is to control the gastric residence time (GRT), i.e., gastroretentive dosage form (GRDF or GRDS). GRDFs extend significantly the period of time over which the drugs may be released. They not only prolong dosing intervals but also increase patient compliance beyond the level of existing controlled release dosage form. Dosage form with prolonged GRT, i.e. GRDFs [1-3].

Mucoadhesive drug delivery systems contain a mucoadhesive polymer that adheres to the gastric mucosal surface and prolong its gastric retention in the GIT. The capability is adhere to the mucus gel layer makes mucoadhesive polymers very useful excipients in the GRRDs [3-5]. These polymers can be natural such as sodium alginate, gelatin, and guar gum or semi-synthetic polymers such as hydroxypropyl methylcellulose, Carbopol, and sodium carboxymethyl cellulose. The adhesion of polymers with mucous membrane may be mediated by hydration, bonding, or receptor. In hydration-mediated adhesion, the hydrophilic polymer becomes sticky and mucoadhesive on hydration. Bonding mediated involves mechanical or chemical bonding. Chemical bonds may involve ionic or covalent bonds or van der Waals forces between the polymer molecule and the mucous membrane [6,7]. Receptor-mediated adhesion takes place between certain polymers and specific receptors expressed on gastric cells $[8,9]$.

\section{MATERIALS AND METHODS}

Materials

The following chemicals were used: Atenolol (Gangwal Chemicals Pvt. Ltd., Mumbai), ethyl cellulose (EC) (Loba Chemie Pvt. Ltd., Mumbai),
Carbopol 940 (Loba Chemie Pvt. Ltd., Mumbai), liquid paraffin (Arora Pharmaceuticals Pvt. Ltd., New Delhi), Span 80 (Central Drug House (P) Ltd., New Delhi), and ethanol (Loba Chemie).

\section{Methods}

Solubility study

The solubility study of drugs was performed in water, methanol, ethanol, acetone, $0.1 \mathrm{~N}$ hydrochloric acid ( $\mathrm{HCl}$ ), phosphate buffer $\mathrm{pH} 6.8$, and phosphate buffer $\mathrm{pH} 7.4$, individually by keeping the drug containing test tube on vortex mixture $[10,11]$.

\section{Determination of melting point}

All dynamic differential scanning calorimetry (DSC) studies of pure drug were carried out on DSC TA-60 Shimadzu thermal analyzer. The instrument was calibrated using high purity indium metal as standard. The scans were taken in nitrogen atmosphere at the heating rate of $10^{\circ} \mathrm{C} / \min [12,13]$

\section{Preparation of $0.1 \mathrm{~N} \mathrm{HCl}$}

A $8.3 \mathrm{ml}$ of concentrated $\mathrm{HCl}$ was taken and diluted with distilled water up to $1000 \mathrm{ml}$ in a volumetric flask.

\section{Scanning of Atenolol in $0.1 \mathrm{~N} \mathrm{HCl}$}

Accurately weight $100 \mathrm{mg}$ of atenolol was diluted in $100 \mathrm{ml} 0.1 \mathrm{~N}$ $\mathrm{HCl}$ solution. From this solution, $1 \mathrm{ml}$ was pipette out in $100 \mathrm{ml}$ volumetric flask and volume was made up to $100 \mathrm{ml}$ with $0.1 \mathrm{~N}$ $\mathrm{HCl}(\mathrm{pH}-1.2)$ (conc.10 $\mu \mathrm{g} / \mathrm{ml}$ ). The solution containing $10 \mu \mathrm{g} / \mathrm{ml}$ of atenolol in $0.1 \mathrm{~N} \mathrm{HCl}$ was scanned over the range of 200-400 nm against $0.1 \mathrm{~N} \mathrm{HCl}$ as blank using double-beam spectrophotometer. The maximum absorbance obtained in graph was considered $\lambda_{\max }$ for pure drug $[14,15]$. 
Standard Calibration Curve in $0.1 \mathrm{~N} \mathrm{HCl}$

Accurately weight $100 \mathrm{mg}$ of atenolol was diluted in $100 \mathrm{ml} 0.1 \mathrm{~N}$ $\mathrm{HCl}$ solution to get a solution containing $1000 \mu \mathrm{g} / \mathrm{ml}$. From the above solution, $10 \mathrm{ml}$ pipette out in $100 \mathrm{ml}$ volumetric flask and diluted up to $100 \mathrm{ml}$ to obtain a concentration of $100 \mu \mathrm{g} / \mathrm{ml}$. This stock solution was used to prepare further dilution of standard solution. Aliquots (0.1$10 \mathrm{ml}$ ) of stock solution were transferred into a series of $10 \mathrm{ml}$ volumetric flasks. The volume was made up to mark with distilled water to produce the concentration ranging from 1 to $100 \mu \mathrm{g} / \mathrm{ml}$. The absorbance of each prepared solution was measured at $\lambda_{\max } 274 \mathrm{~nm}$ using double-beam spectrophotometer against $0.1 \mathrm{~N} \mathrm{HCl}$ as blank $[16,17]$.

\section{Fourier-Transform Infrared (FT-IR) Spectroscopy}

The selected drug and polymers were characterized by FT-IR spectroscopy and the FT-IR spectra of the pure drug atenolol with used polymers such as EC and Carbopol 934 [18]. The spectrum was recorded for pure drug, physical mixture of combination of all the excipients and drug. The scanning range was $4000-500 \mathrm{~cm}^{-1}[19,20]$.

Formulation Development of Microparticles Containing Atenolol Using Central Composite Design (CCD).

The microspheres of combined polymers are designed according to $2^{2}$ factorial CCD. EC concentration and surfactant concentration were the two independent variables. The selected variables with the actual and coded levels as per the design are represented in Table 1 . The higher, lower, and the intermediate levels of each variable are coded as $+1,-1$, and 0 , respectively $[21,22]$. Final formulation of all batches with their respective amounts is represented in Table 2.

\section{Preparation of Microparticles}

The microparticles were prepared using solvent evaporation technique with polymers such as EC and Carbopol 934. The organic solvent system used was ethanol $20 \mathrm{ml}$. The polymers were dissolved in the organic solvent with continuous stirring using propeller type agitator. Slowly the drug was added with continuous stirring. The mixture was poured in $250 \mathrm{ml}$ liquid paraffin containing $3 \%(\mathrm{w} / \mathrm{v})$ Span 80 maintained at a temperature $50-60^{\circ} \mathrm{C}$ and subsequently stirred at a $900 \mathrm{rpm}$ for $2.5 \mathrm{~h}$. Continuous mixing and evaluated temperature may be employed to evaporate ethanol completely and microparticles were formed. The hardened microparticles were collected by filtration assembly and washed with small portions of n-hexane and air dried [23]. Total 13 formulation were prepared AT- 1 to AT-13 (Composition shown in Table 3).

\section{Characterization of Formulation}

\section{$\%$ yield analysis}

The prepared mucoadhesive microparticles were collected and weighed. The measured weight was divided by total amount of all non-volatile components, which were used for the preparation of microparticles [24]. The \% yield was calculated using following formula:

$$
\% \text { yeild }=\frac{\text { Actual weight of product }}{\text { Total weight of non volatile excipients and drugs }} \times 100
$$

Particle Size Analysis

Measurements of the particle size distribution of microparticles were carried out with a projection microscope stage micrometer which was used to calculate calibration factor. The particle size was calculated by multiplying the number of divisions of the ocular disc occupied by the particle with calibration factor. Fifty randomly chosen particles were taken to measure their individual size [25].

$$
\% \text { yeild }=\frac{}{\text { Total }}
$$

Where,

$\mathrm{n}=$ number of microspheres observed

$\mathrm{d}=$ mean size range

\section{Drug Entrapment Efficiency}

Microparticles (100 mg) were weighed and crushed with mortar and pestle, then were suspended in $10 \mathrm{ml}$ of $0.1 \mathrm{~N} \mathrm{HCl}$. After $24 \mathrm{~h}$, the solution was filtered and the filtrate was diluted up to $100 \mathrm{ml}$ with 0.1 $\mathrm{N} \mathrm{HCl}$. Next, $2 \mathrm{ml}$ from this solution was picked up; this filtrate was diluted up to appropriate dilution $(10 \mathrm{ml})$; and the drug concentration was measured spectrophotometrically at $274 \mathrm{~nm}$ against $0.1 \mathrm{~N} \mathrm{HCI}$ as a blank. Theoretical drug loading was determined by entire drug present in the polymer solution in the microparticles [26,27]. Entrapment efficiency was calculated by formula:

$$
\text { Drug entrapment efficiency }=\frac{\text { Calculated drug concentration }}{\text { Theoretical drug concentration }} \times 100
$$

\section{Flow Properties}

Angle of repose

For the measurement of angle of repose, a glass funnel was secured with its tip at a given height $(\mathrm{h})$ above a piece of graph paper placed on a horizontal surface. Microparticles were poured through the funnel until the apex of the conical pile touched the tip of the funnel [28,29]. The angle of repose was calculated with the formula:

$$
\theta=\tan ^{-1}(\mathrm{~h} / \mathrm{r})
$$

Where,

$\theta=$ angle of repose

$\mathrm{h}=$ height of the heap

$\mathrm{r}=$ radius of the heap

\section{Bulk Density}

For the determination of bulk density, weight quantities of microparticles were introduced into graduated measuring cylinder and were tapped mechanically or either manually till a constant volume was obtained. The bulk density of microparticles depends on particle size

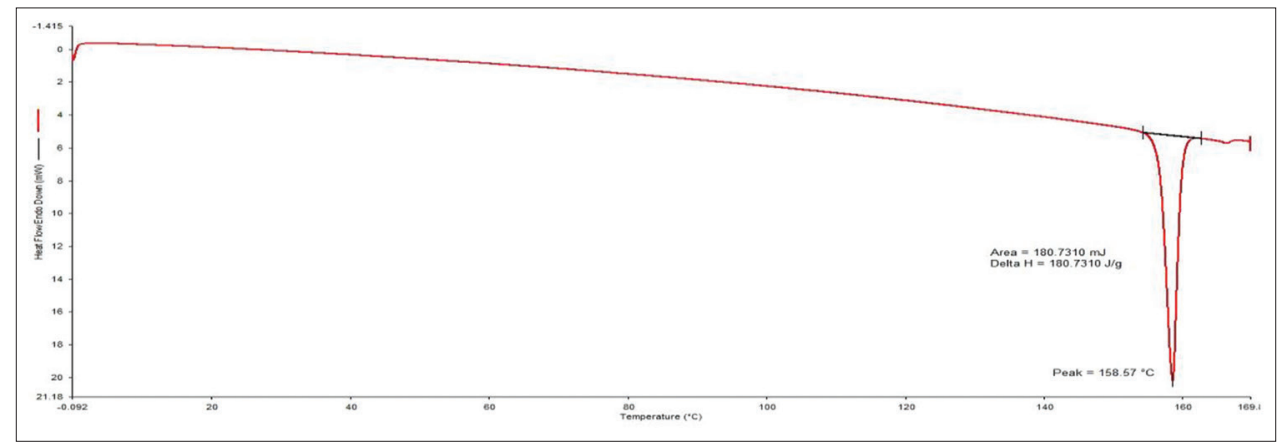

Fig. 1: Differential scanning calorimetry of atenolol 
and distribution and particle shape [30,31]. Bulk density is calculated by formula:

$$
\text { Bulk density }=\frac{\text { Mass of microparticles }}{\text { Bulk volume of microparticles }}
$$

\section{Tapped Density}

The cylinder containing known amount of microparticles was given 100 tabs on tap density apparatus [32]. It calculated by formula:

$$
\text { Tapped density }=\frac{\text { Mass of microparticles }}{\text { Volume of micropraticles after tapping }}
$$

\section{Hausner's Ratio}

It indicates the flow properties of the granules and is measured by the ratio of tapped density to the bulk density. Hausner value $<1.25$ indicates good flow, whereas greater than 1.25 indicates poor flow $[33,34]$. Hausner's ratio is calculated by formula:

$$
\text { Hausner's ratio }=\frac{\text { Tapped density }}{\text { Bulk density }}
$$

\section{Compressibility Index (Carr's Index)}

Compressibility index is an important measure that can be obtained from the bulk and tapped densities. In theory, the less compressible a material the more flowable it is. A material having values of less than $20 \%$ has good flow property [35].

$$
\% \text { Compressibilty index }=\frac{\text { Tapped density }- \text { Bulk density }}{\text { Tapped density }} \times 100
$$

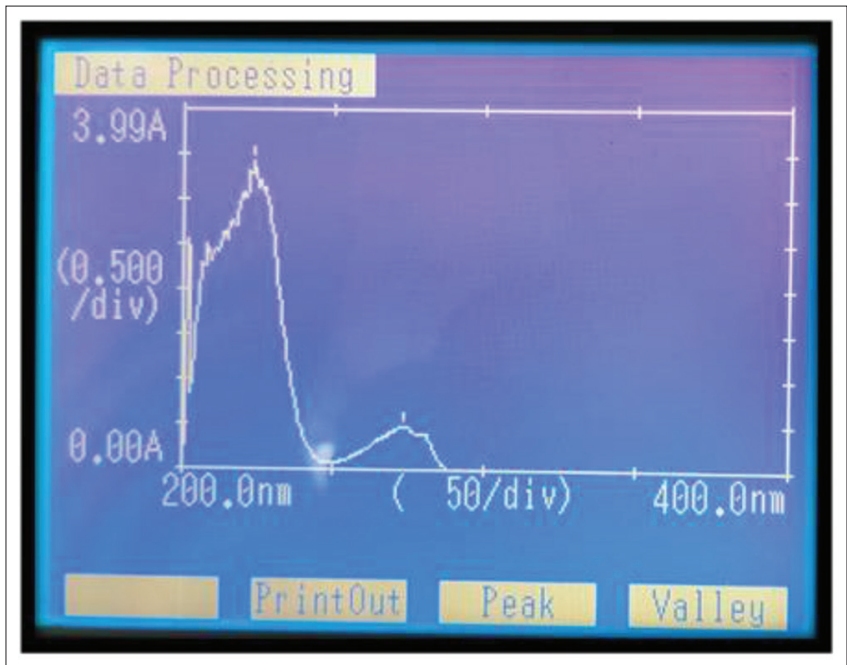

Fig. 2: $\lambda_{\text {max }}$ of atenolol in $0.1 \mathrm{~N}$ hydrochloric acid
In vitro Drug Release Study

Dissolution studies were carried out for all the formulations employing USP XXIII apparatus (paddle method) at $37 \pm 0.5^{\circ} \mathrm{C}$ rotated at constant speed of $50 \mathrm{rpm}$ using $900 \mathrm{ml}$ of $0.1 \mathrm{~N} \mathrm{HCl}$ as the dissolution medium for $24 \mathrm{~h}$. A sample of $100 \mathrm{mg}$ of microspheres was used in each test. An aliquot of the sample was periodically withdrawn at suitable time interval and the volume was replaced with fresh dissolution medium to maintain the sink condition. The samples were suitably diluted and analyzed at $274 \mathrm{~nm}$ using $0.1 \mathrm{~N} \mathrm{HCl}$ as blank using double-beam ultraviolet (UV)-visible spectrophotometer [36-39,15].

\section{Drug Release Kinetics}

In the present study, raw data obtained from in vitro release studies were analyzed wherein data were fitted to different equations and kinetic models to calculate the percentage drug release and release kinetics of atenolol from microparticles. Table shows the cumulative percentage drug release, log of cumulative percentage drug release. and remaining at various time points $[39,28,35]$. The results of in vitro release profile of optimized batch were fitted into four models of data treatment as follows:

- Cumulative percentage drug released versus time (zero-order kinetic model)

- Log cumulative percentage drug remaining versus time (first-order kinetics)

- Cumulative percentage drug released versus square root of time (Higuchi model)

- Log cumulative percentage drug remaining versus log time (Korsmeyer-Peppas model).

\section{Scanning Electron Microscopy (SEM)}

The surface morphology of the optimized drug-loaded microsphere was investigated by SEM. Studies using SEM provided a better understanding of the morphological characteristics of the microparticles [40].

\section{RESULTS AND DISCUSSION}

\section{Solubility}

Atenolol was found to be soluble in methanol, $0.1 \mathrm{~N} \mathrm{HCl}$, water, ethanol, and phosphate buffer $\mathrm{pH} 6.8$.

\section{Melting Point}

DSC curve of atenolol showed a sharp endothermic peak near $158.57^{\circ} \mathrm{C}$ in Fig. 1 that is indicative of its melting temperature.

\section{Analytical Methodology}

Determination of absorption maxima $\left(\lambda_{\max }\right)$ of atenolol in $0.1 \mathrm{~N} \mathrm{HCl}$

The solution of $20 \mu \mathrm{g} / \mathrm{ml}$ was scanned between 200 and $400 \mathrm{~nm}$. The $\lambda_{\max }$ was found to be $274 \mathrm{~nm}$ which indicates purity of sample drug atenolol. Absorption maxima of atenolol is represented in Fig. 2. The calibration curve of the drug shown in Fig. 3.

The absorbance of the drug solution was estimated at $\lambda_{\max } 274 \mathrm{~nm}$ in Shimadzu UV-1700 spectrophotometer of various concentration shown in Table 4 against $0.1 \mathrm{~N} \mathrm{HCl}(1.2 \mathrm{pH})$ as blank.

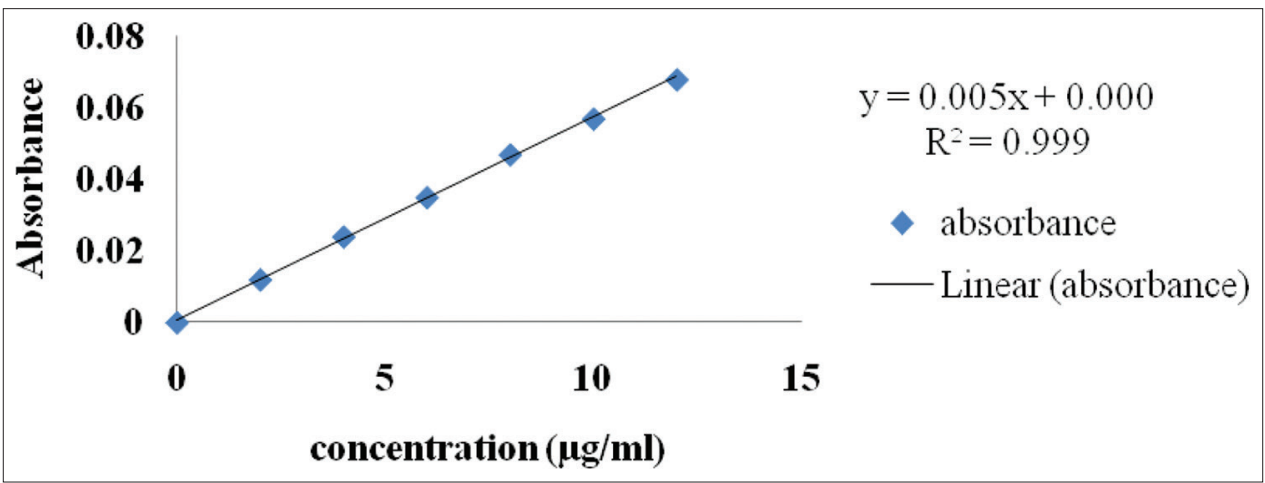

Fig. 3: Standard plot of atenolol in $0.1 \mathrm{~N}$ hydrochloric acid 


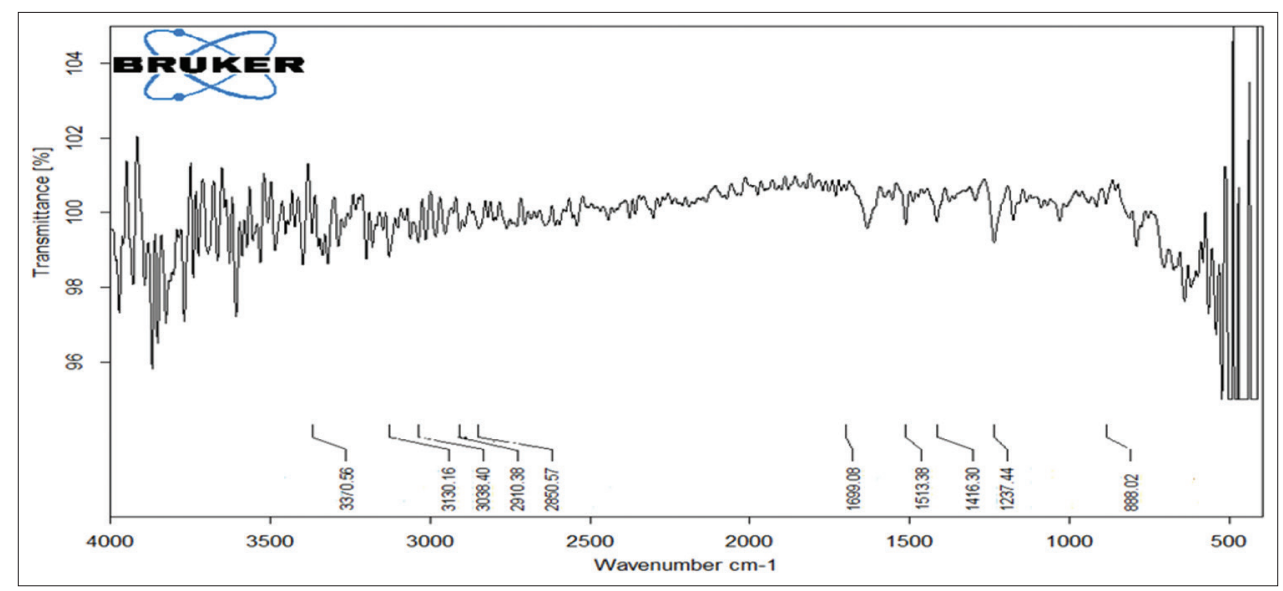

Fig. 4: Fourier transform infrared spectrum of atenolol

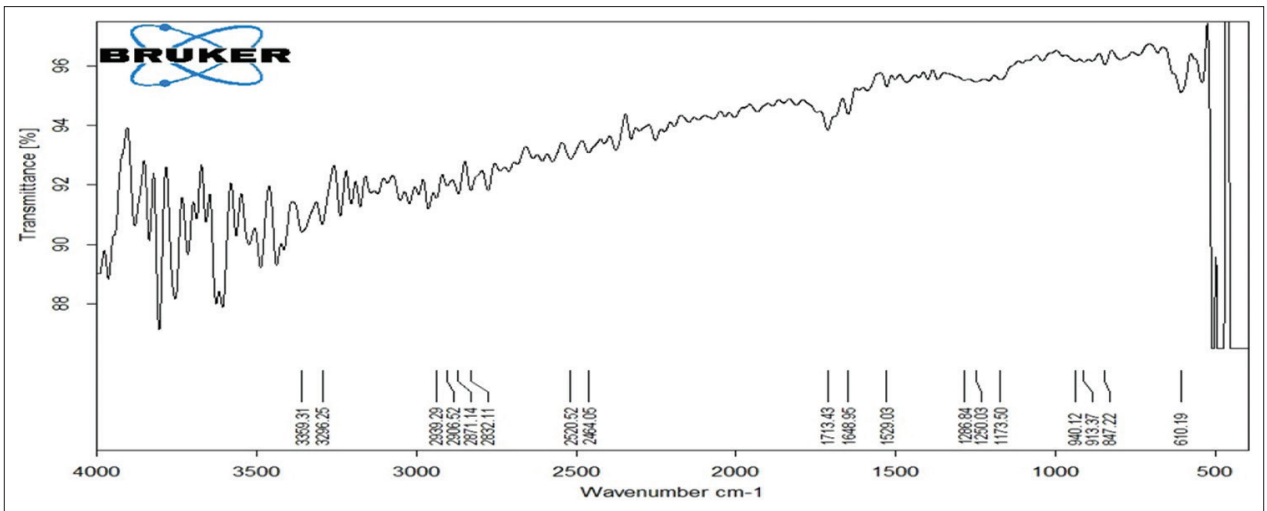

Fig. 5: Fourier transform infrared spectrum of Carbopol 940

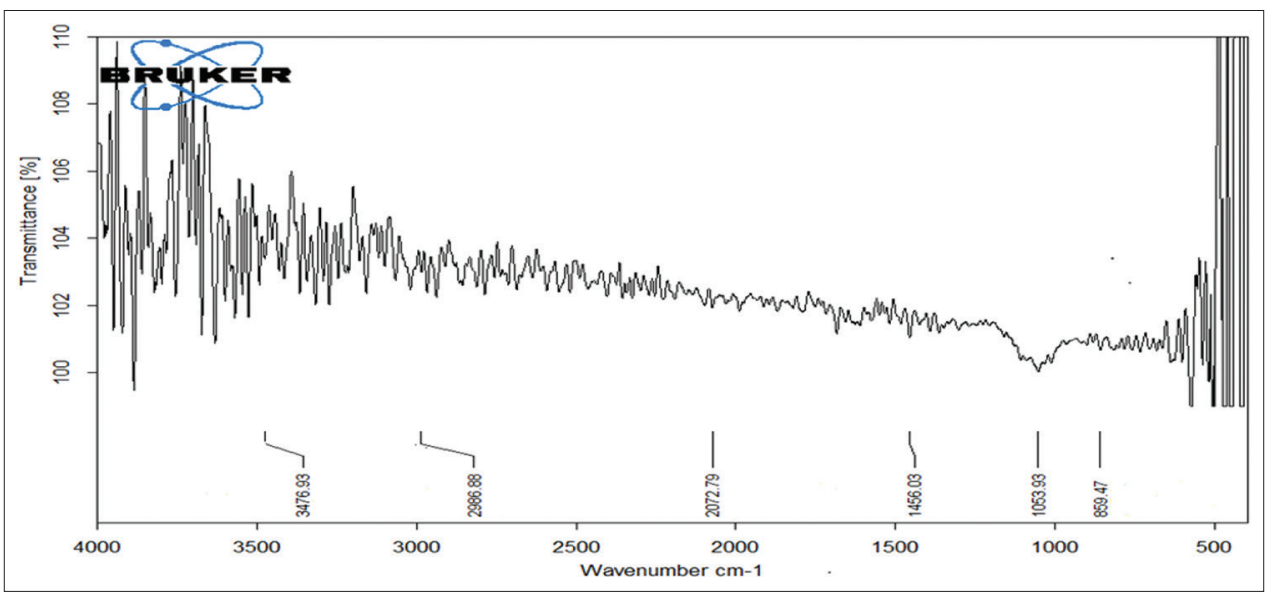

Fig. 6: Fourier transform infrared spectrum of ethyl cellulose

Table 1: Independent variables in CCD

\begin{tabular}{llll}
\hline \multicolumn{2}{l}{ Correlation of actual and coded value } \\
\hline Factor & $\begin{array}{l}\text { Coded } \\
\text { value }\end{array}$ & \multicolumn{2}{l}{ Actual value } \\
\cline { 3 - 4 } & & EC $(\mathbf{m g})\left(\mathbf{X}_{\mathbf{1}}\right)$ & Surfactant conc. $(\% \mathbf{w} / \mathbf{v})\left(\mathbf{X}_{\mathbf{2}}\right)$ \\
\hline Low & -1 & 450 & 2 \\
Medium & 0 & 675 & 3 \\
High & +1 & 900 & 4 \\
\hline
\end{tabular}

CCD: Central composite design, EC: Ethyl cellulose
FT-IR Spectral Studies of Pure Active Pharmaceutical Ingredient (API) and Physical Mixture

The spectra obtained from FT-IR spectroscopy studied at wavelength from $4000 \mathrm{~cm}^{-1}$ to $400 \mathrm{~cm}^{-1}$ are shown in Figs. 4-7. FT-IR analysis revealed that there was no interaction between the drug and polymers; thus, these polymers can be conveniently used in further development of stomach specific mucoadhesive atenolol microparticles. In the present study, it has been observed that there are no chemical and physical interactions because of some bond formation between drug and polymers. 


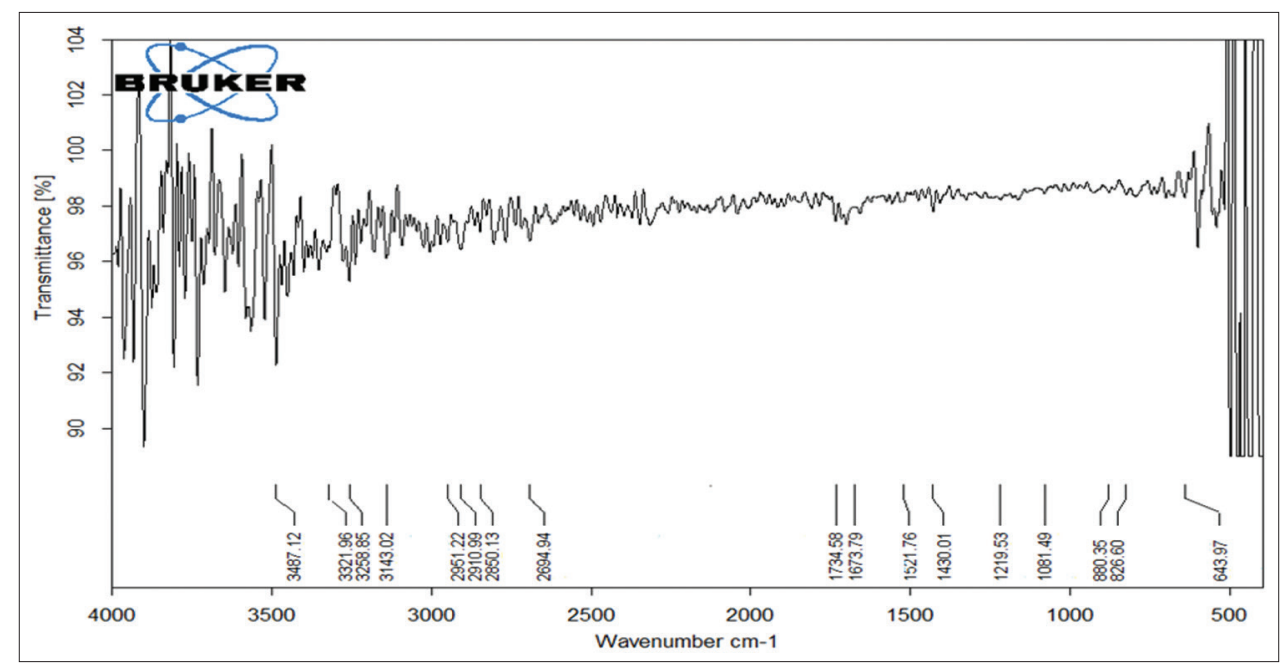

Fig. 7: Fourier transform infrared spectrum of physical mixture

Table 2: Formulation selected using CCD

\begin{tabular}{llll}
\hline S. No. & Formulation code & \multicolumn{2}{c}{ Independent factor } \\
\cline { 3 - 4 } & & A: EC & B: Surfactant conc. \\
\hline 1. & AT-1 & -1.000 & -1.000 \\
2. & AT-2 & 1.000 & -1.000 \\
3. & AT-3 & -1.000 & 1.000 \\
4. & AT-4 & 1.000 & 1.000 \\
5. & AT-5 & -1.414 & 0.000 \\
6. & AT-6 & 1.414 & 0.000 \\
7. & AT-7 & 0.000 & -1.414 \\
8. & AT-8 & 0.000 & 1.414 \\
9. & AT-9 & 0.000 & 0.000 \\
10. & AT-10 & 0.000 & 0.000 \\
11. & AT-11 & 0.000 & 0.000 \\
12. & AT-12 & 0.000 & 0.000 \\
13. & AT-13 & 0.000 & 0.000 \\
\hline
\end{tabular}

CCD: Central composite design, EC: Ethyl cellulose

\section{In vitro Drug Release}

The release profiles of all microparticles are illustrated in Fig. 8. Initial drug release for the microparticles formulations is high. As more drugs are release from the microparticles, more channels and pores are probably produced, contributing to faster drug release rates. The reason for the burst release could be due to the presence of some atenolol particles close to the surface of the microparticles. When particles are prepared by $\mathrm{O}_{1} / \mathrm{O}_{2}$ method, water-soluble drugs do not have tendency to migrate to the non-polar medium, thereby concentrating at surface of the microparticles and inducing the burst effect. Amount of drug release after $2 \mathrm{~h}$ shows $29.5 \pm 0.78-35 \pm 0.90$ (\%) and after $24 \mathrm{~h}$ of different batches was in the range of $61.32 \pm 0.99$ $89.27 \pm 1.57(\%)$.

\section{Particles Size Analysis}

Microparticles were analyzed with calibrated optical microscope, fitted with a stage and an ocular micrometer. The particle size of microparticles was in the range of 240.7-374.1 $\mu \mathrm{m}$.

The microparticles size depended on the rate of polymer solidification. Deposition of polymer within droplet with the help of ethanol because ethanol is evaporated. The partitioning rate of ethanol from emulsion to external phase could be the main factor controlling the deposition rate of the polymers.

\section{Responses Analysis of Optimization}

Statistical validation of polynomial equation generated (Table 5) by Design-Expert at R11 was established on the basis of ANOVA provision in the software. A total of 13 run (AT-1 to AT-13) were generated. The 3-D response surface plots were obtained using this software. The resultant experiment data of response properties were compared with that of the predicted values.

\section{Evaluation of Results}

The observed value of responses (\% drug entrapment efficiency Fig. 9 and $\%$ drug release) Fig. 8 was further analyzed statistically to evaluate effect of various factors and interaction of factors using design of experiments. The optimized formulation was selected using statistical screening.

\section{Optimization Data Analysis}

For the design, linear regression analysis method was applied using the Design-Expert software to the full polynomial equation with added interaction terms.

Polynomial equation:

Response 1; Drug release $=+141.28913-0.092751 \mathrm{~A}-14.54967 \mathrm{~B}+$ $0.018933 \mathrm{AB}$

Response 2; Entrapment efficiency $=+0.212944+0.189249 \mathrm{~A}$ $+7.49470 \mathrm{~B}-0.000089 \mathrm{AB}-0.000127 \mathrm{~A}^{2}-1.74500 \mathrm{~B}^{2}$

\section{Optimization formulation}

\section{Final Optimized Formulation Prepared}

Final batch of atenolol microparticles was prepared by emulsionsolvent evaporation method. Optimized formulation was prepared by taking $520 \mathrm{mg}$ EC and $2.36 \mathrm{mg}$ surfactant and was evaluated (Fig. 10).

\section{Evaluation of Optimized Batch}

Predicted and obtained values of responses of drug release \% and Entrapment efficiency \% given in Table 6 . The obtained value is same as predicted value.

\section{Compression of Microparticles into Disc}

Disc formulations were prepared by direct compression technique from microparticles. Each disc contained $100 \mathrm{mg}$ of atenolol microparticles. The disc round and flat with an average diameter of $9.4 \mathrm{~mm}$ and disc were compressed with a constant compression force (3.5 tones). Disc form of microparticles of atenolol shown in Fig. 11.

\section{Evaluation of Optimized Batch}

\section{Drug entrapment efficiency}

The percentage entrapment efficiency was found to be $72.02 \%$. This shows that $72.02 \%$ of the drug is entrapped into the microparticles. 


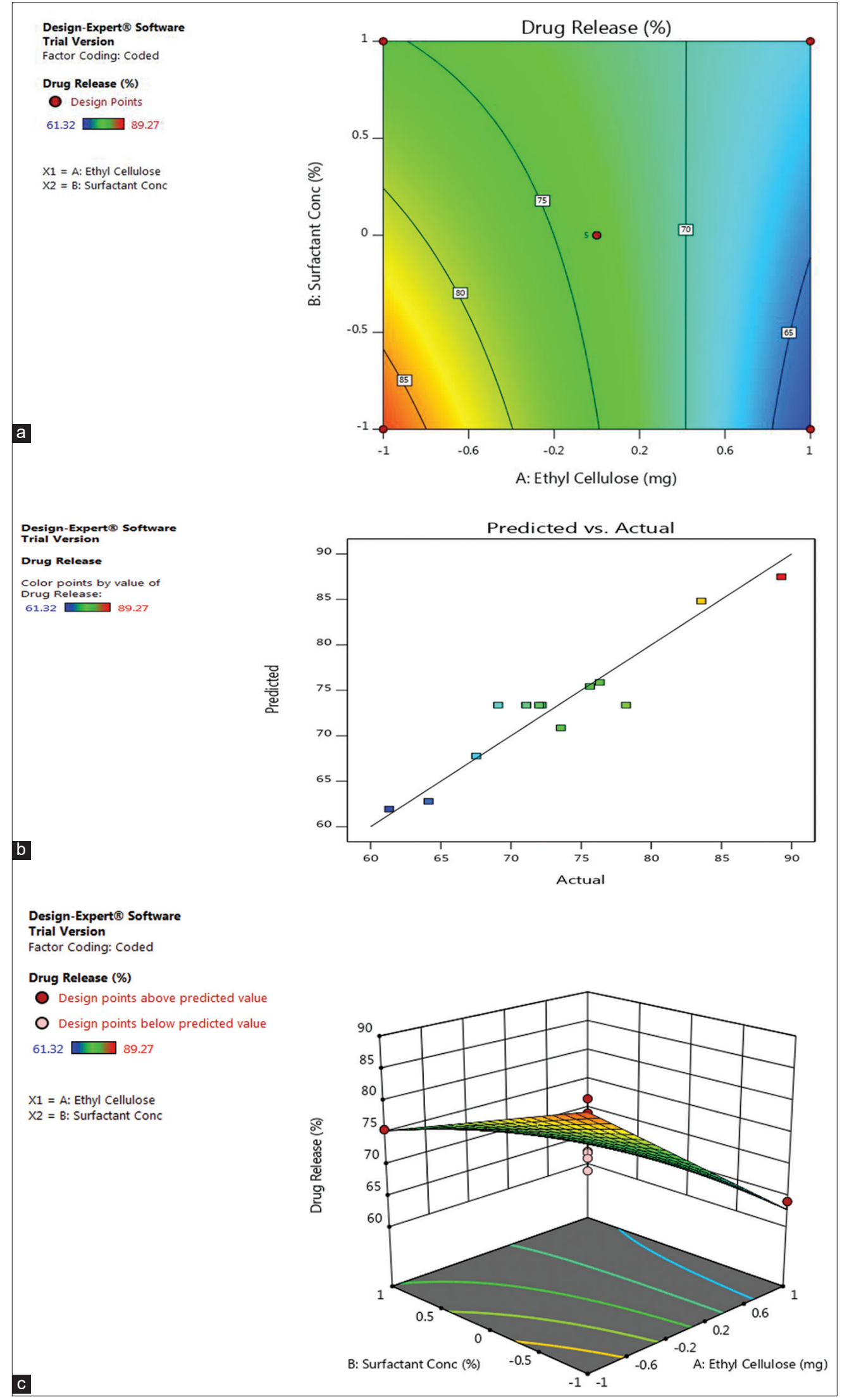

Fig. 8: Various plots showing influence of surfactant conc. and ethyl cellulose on $\%$ drug release (a) contour plot, (b) predicted versus actual, (c) response surface plot 


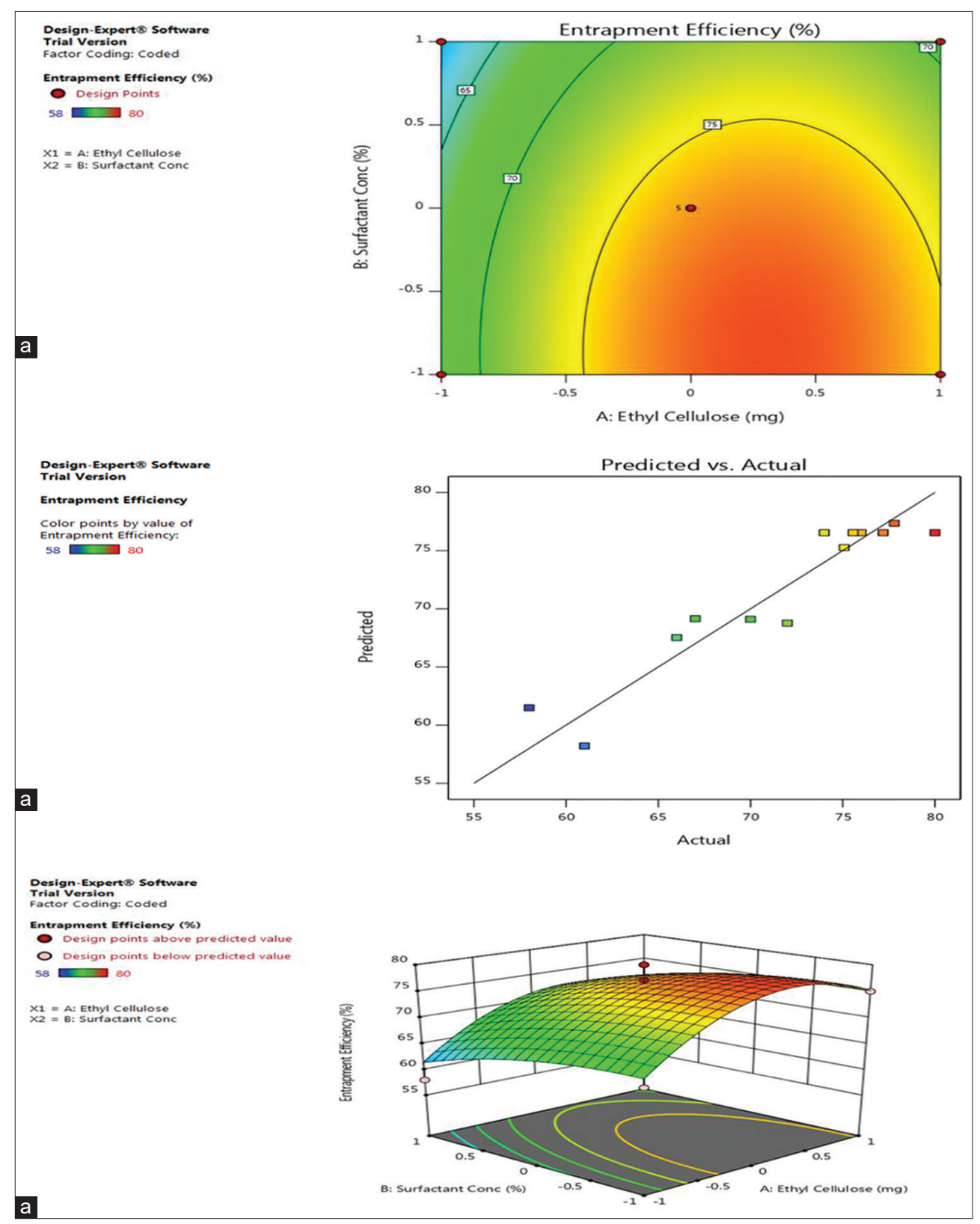

Fig. 9: Various plots showing influence of surfactant conc. and ethyl cellulose on $\%$ entrapment efficiency (a) contour plot, (b) predicted versus actual, (c) response surface plot

Table 3: Composition of different microparticles formulations with code using CCD

\begin{tabular}{lllllll}
\hline Formulation code & Drug $\mathbf{( m g )}$ & EC $(\mathbf{m g})$ & Carbopol $934 \mathbf{( m g})$ & Liquid paraffin $(\mathbf{m l})$ & Ethanol $(\mathbf{m l})$ & Span $\mathbf{8 0}(\mathbf{\%} \mathbf{w} / \mathbf{v})$ \\
\hline AT-1 & 50 & 450 & 225 & 125 & 20 & 2 \\
AT-2 & 50 & 900 & 225 & 125 & 20 & 2 \\
AT-3 & 50 & 450 & 225 & 125 & 20 & 4 \\
AT-4 & 50 & 900 & 225 & 125 & 20 & 4 \\
AT-5 & 50 & 356.80 & 225 & 125 & 20 & 3 \\
AT-6 & 50 & 993.20 & 225 & 125 & 20 & 3 \\
AT-7 & 50 & 675 & 225 & 125 & 20 & 1.59 \\
AT-8 & 50 & 675 & 225 & 125 & 20 & 4.41 \\
AT-9 & 50 & 675 & 225 & 125 & 20 & 3 \\
AT-10 & 50 & 675 & 225 & 125 & 20 & 3 \\
AT-11 & 50 & 675 & 225 & 125 & 20 & 3 \\
AT-12 & 50 & 675 & 225 & 225 & 20 & 3 \\
AT-13 & 50 & 675 & & &
\end{tabular}

CCD: Central composite design, EC: Ethyl cellulose 


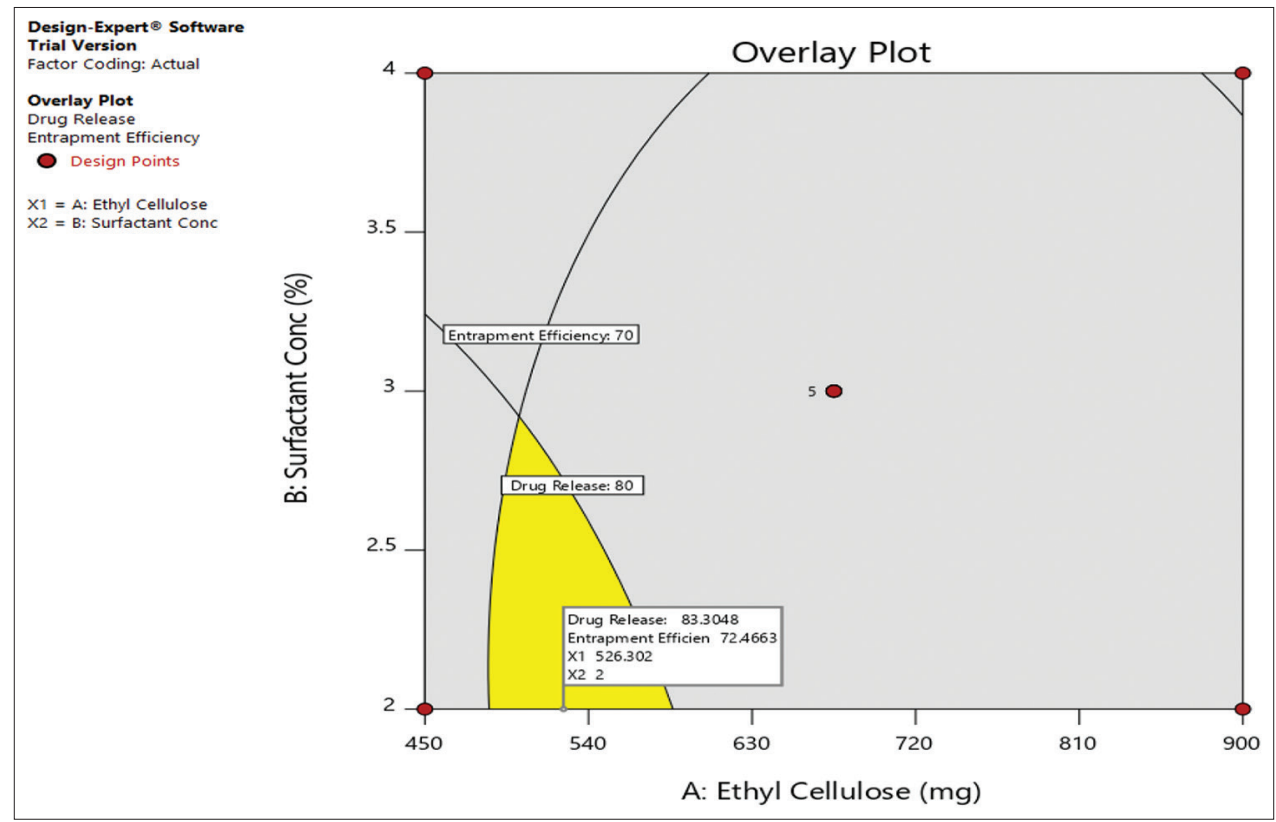

Fig. 10: Optimized formulation solution with desirability

Table 4: Concentration and corresponding absorbance in $\mathrm{HCl}$

\begin{tabular}{lll}
\hline S. No. & Concentration $(\boldsymbol{\mu g} / \mathbf{m l})$ & Absorbance at $\mathbf{2 7 4} \mathbf{n m} \pm \mathbf{S D}$ \\
\hline 1. & 0 & 0 \\
2. & 2 & $0.012 \pm 0.001$ \\
3. & 4 & $0.024 \pm 0.002$ \\
4. & 6 & $0.035 \pm 0.004$ \\
5. & 8 & $0.047 \pm 0.006$ \\
6. & 10 & $0.057 \pm 0.005$ \\
7. & 12 & $0.068 \pm 0.007$ \\
\hline
\end{tabular}

HCl: Hydrochloric acid

Table 5: The composition and observed response from randomized runs in CCD

\begin{tabular}{|c|c|c|c|c|}
\hline \multirow[t]{3}{*}{ Run } & Factor 1 & Factor 2 & Response 1 & Response 2 \\
\hline & A: EC & $\begin{array}{l}\text { B: Surfactant } \\
\text { conc. }\end{array}$ & $\begin{array}{l}\text { Drug } \\
\text { release }\end{array}$ & $\begin{array}{l}\text { Entrapment } \\
\text { efficiency }\end{array}$ \\
\hline & Mg & $\%$ & $\%$ & $\%$ \\
\hline 1. & 0.000 & 0.000 & 71.09 & 80 \\
\hline 2. & 0.000 & 0.000 & 69.08 & 75.56 \\
\hline 3. & 0.000 & 0.000 & 72 & 74 \\
\hline 4. & -1.000 & 1.000 & 75.63 & 58 \\
\hline 5. & 0.000 & 0.000 & 78.2 & 77.19 \\
\hline 6. & 1.414 & 0.000 & 61.32 & 70 \\
\hline 7. & 0.000 & 1.414 & 73.55 & 72 \\
\hline 8. & -1.414 & 0.000 & 83.56 & 61 \\
\hline 9. & 1.000 & 1.000 & 67.52 & 67 \\
\hline 10. & 0.000 & -1.414 & 76.32 & 77.8 \\
\hline 11. & 1.000 & -1.000 & 64.12 & 75.08 \\
\hline 12. & 0.000 & 0.000 & 72.19 & 76 \\
\hline 13. & -1.000 & -1.000 & 89.27 & 66 \\
\hline
\end{tabular}

CCD: Central composite design, EC: Ethyl cellulose

Table 6: Predicted and obtained values of responses

\begin{tabular}{lll}
\hline Response & Predicted & Obtained \\
\hline Drug release \% & 81.95 & 81.94 \\
Entrapment efficiency \% & 72.07 & 72.07 \\
\hline
\end{tabular}

Table 7: Kinetics of drug release of atenolol microparticles

\begin{tabular}{ll}
\hline Plot & $\mathbf{R}^{2}$ \\
\hline Zero order & 0.696 \\
First order & 0.774 \\
Higuchi & 0.837 \\
Peppas & 0.989 \\
\hline
\end{tabular}

$\%$ yield

The percentage yield of atenolol microparticles was found to be $94.26 \%$.

Particle size

The particle size yield of atenolol microparticles was found to be $292.5 \mu \mathrm{m}$.

Swelling index

The swelling index of atenolol microparticles was found to be $95.6 \%$.

Angle of repose

The angle of repose of atenolol microparticles was found to be $18.25^{\circ} \theta$. It indicates the good flow property for microparticles.

\section{Bulk density}

Bulk density of optimized batch was found to be $0.131 \mathrm{~g} / \mathrm{cm}^{3}$.

True density

True density of optimized batch was found to be $0.156 \mathrm{~g} / \mathrm{cm}^{3}$.

Carr's index

Carr's index was found to be $16.02 \%$. This was $<20$ indicating good flow characterizes.

\section{Hausner's ratio}

Hausner's ratio was found to be 1.19 .

In vitro Dissolution Study and Kinetic Modeling of Drug Release Studies

The optimized batch prepared mucoadhesive microparticles of atenolol were subjected to in vitro release studies, these studies were carried 


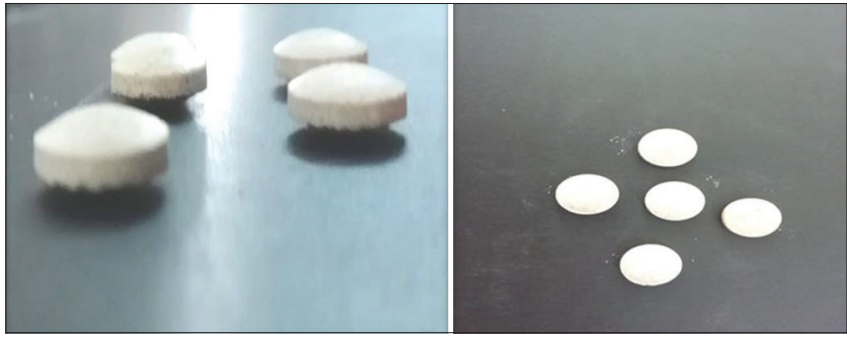

Fig. 11: Disc form of microparticles of atenolol (side and top view)

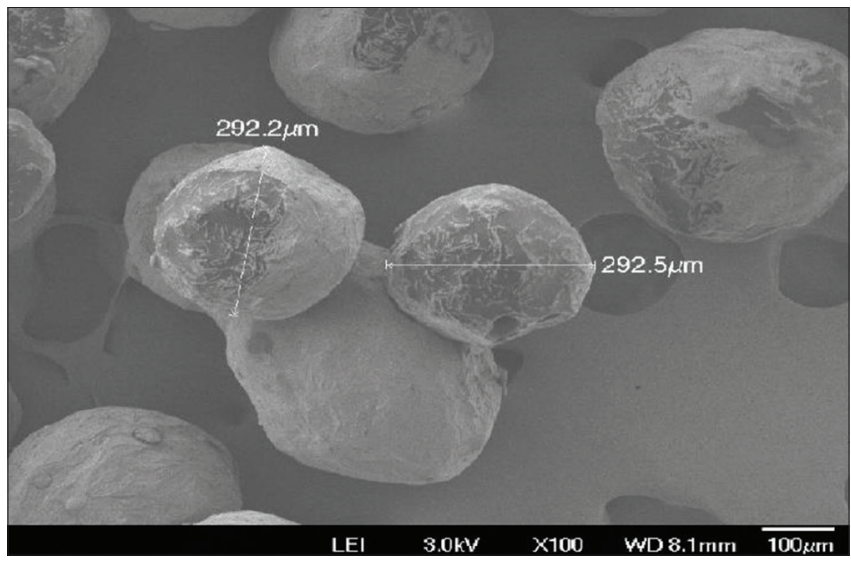

Fig. 12: Scanning electron microscopic picture of atenolol microparticles

out using Shimadzu, dissolution apparatus with $0.1 \mathrm{~N} \mathrm{HCl}(\mathrm{pH} 1.2)$ of dissolution media. The kinetic values obtained for formulation are shown in Table 7. The values of in vitro release were attempted to fit into various mathematical models.

The data obtained for in vitro release were fitted into equations for zero-order, first-order, Higuchi, and Korsmeyer-Peppas release models. The interpretation of data was based on the value of the resulting regression coefficients.

From these values, it was observed that the Korsmeyer-Peppas release model was found to be best suited with $\mathrm{R}^{2}=0.989$.

\section{SEM}

Scanning electron photomicrographs of optimized drug-loaded mucoadhesive microparticles are shown in Fig. 12. The surface morphology of prepared microparticles shows spherical shape with a slightly rough surface which may be because of surface-associated drug crystals.

\section{CONCLUSION}

The objective of this project was formulation and evaluation of microparticles containing atenolol. Atenolol was selected for the formulation of oral mucoadhesive drug delivery system. Antihypertensive drugs are predominantly used to treat hypertension and prevent complications of high blood pressure, such as stroke and myocardial infarction.

To formulate optimize mucoadhesive microparticles containing atenolol as API, CCD was employed using EC polymer and Span 80 as surfactant (independent variables) and other excipients Carbopol 934, liquid paraffin, ethanol, and n-hexane. The percentage drug entrapment efficiency and percentage drug release were selected as dependent variables and the best formulation was selected by the Design-Expert version 11. The optimized formulation of microparticles containing atenolol was found to be homogeneous, good appearance and had well flow properties and better release kinetics.
Thus, it may be concluded that atenolol is believed to be a widely used medication for antihypertensive activity. Further studies (such as animal testing) can be conducted to make it viable for commercial product.

\section{ACKNOWLEDGMENT}

The author would like to thank my guide Mr. Sunil K Batra for providing a platform and facility to conduct research work. The authors would like to thank Gangwal Chemicals Pvt. Ltd., Mumbai, for providing a gift sample of atenolol.

\section{AUTHORS' CONTRIBUTIONS}

All the authors have contributed equally.

\section{CONFLICTS OF INTEREST}

The authors declare no conflicts of interest.

\section{REFERENCES}

1. Nayak AK, Maji R, Das B. Gastroretentive drug delivery systems: A review. Asian J Pharm Clin Res 2010;3:1-10.

2. Meenakshi J, Ujjwal N, Jyotsana $\mathrm{K}$, Devendra S. A review: Gastroretentive drug delivery system (grdds). Indian J Pharm Biol Res 2015;3:82-92

3. Havaldar VD, Kulkarni AS, Dias RJ, Aloorkar NH, Mali KK. Floating matrix tablets of atenolol: Formulation and in vitro evaluation. Asian J Pharm 2009;3:284-91

4. Pranati S, Rishabha M, Sharad V. Formulation development and evaluation of atenolol fast disintegrating tablets for treatment of hypertension. J Chronother Drug Deliv 2010;1:36-42.

5. Yadava N, Mohiteb DD, Pawarb KR, Pawarb UR, Bhiseb SB, Sande TA. Synthesis and characterization of sustained release atenolol microspheres by solvent evaporation technique. J Pharm Sci Technol 2011;3:559-62.

6. Tadwee IK, Sadhana S, Shekhar T, Gupta SK, Suhas V, Ashok S. Formulation development and evaluation of spray dried nasal mucodhesive microspheres of atenolol. Int $\mathrm{J}$ Pharm Res All Sci $2011 ; 1: 34-40$

7. Shahi SR, Tribhuwan SD, Tadwee IK, Gupta SK, Zadbuke SN, Shivanikar SS. Formulation of atenolol mucoadhesive microspheres for nasal delivery by spray drying technique: In vitro/ex vivo evaluation. Pharm Sin 2011;2:54-63.

8. Patil PB, Gawali VU, Patil HN, Hardikar SR, Bhosale AV. Preparation and evaluation of mucoadhesive microspheres of atenolol and propranolol. Int J Pharm Tech Res 2009;1:639-43.

9. Sanjay D, Sankha C, Bhaskar M. Formulation and evaluation of fixeddose combination of bilayer gastroretentive matrix tablet containing atorvastatin as fast-release and atenolol as sustained-release. Biomed Res Int 2014;2014:396106.

10. Adity B, Sultana NR, Tajnin A, Sharmin S. Design and development of atenolol matrix tablet employing natural and synthetic polymers. J Appl Pharm Sci 2013;3:103-8.

11. Badola A, Chakraborthy GS. Development and characterization of atenolol and indapamide in their combined dosage form using different polymers. World J Pharm Pharm Sci 2014;3:1206-27.

12. Anepu S, Duppala L, Nikhil J, Devi SJ. Formulation and evaluation of gastro retentive matrix tablets of atenolol using melt granulation technique. Int J Pharm Sci Res 2016;7:1081-92.

13. Anepu S, Duppala L, Nikhil J, Devi SJ. Formulation and evaluation of gastro retentive matrix tablets of atenolol using melt granulation technique. Int J Pharm Sci Res 2016;7:1081-92.

14. Jaybir S, Meenakshi B. Formulation and evaluation of atenolol mouth dissolving tablet. Chem Biol Interface 2017;7:323-7.

15. Khonsari F, Zakeri-Milani P, Jelvehgari M. Formulation and evaluation of in vitro characterization of gastic-mucoadhesive microparticles/discs containing metformin. Iran J Pharm Res 2014;13:67-80.

16. Surendranaths B, Mohan VM, Abbulu K. Formulation and evaluation of sustained release microspheres of propranolol. World J Pharm Pharm Sci 2017;6:1497-507.

17. Shivpoojan K, Jony G, Shweta S, Narendra PK, Mahendra T. Method development and validation of atenolol drug by spectrophotometric and HPLC technique in forensic application. Int J Sci Res 2013;2013:1731-5.

18. Gite S, Shinkar DM, Saudagar RB. Development and evaluation of 
mucoadhesive tablets of atenolol and its B-cyclodextrin complex. Asian J Biomed Pharm Sci 2014;4:25-32.

19. Venkatalakshmi R, Sasikala C, Yajaman S. Formulation and evaluation of bioerodible bilayered buccal tablets containing atenolol. J Chem Pharm Sci 2017;10:1170-3.

20. Perumal D. Microencapsulation of ibuprofen and Eudragit RS 100 by the emulsion solvent diffusion technique. Int J Pharm 2001;218:1-11.

21. Kuldip P, Tekade BW, Thakare VM, Patil VR. Formulation and evaluation of atenolol floating microsphere. Pharmatutor 2018;???:1-10.

22. Reddy AP, Shaik US, Moodu M, Gaddam S, Anga M. Development and evaluation of sustained release microparticles of atenolol of gastrointestinal delivery. GSC Biol Pharm Sci 2018;3:1-5.

23. Kumar S, Reddy J, Sekhar PC. Design, development and characterisation of mucoadhesive microsphere of naproxen sodium by HPMC K15M as polymer. J Pharm Res 2011;4:3943-7.

24. Satyanasrayana L, Sandeepthi N. Formulation and evaluation of atenolol floating microspheres. Indo Am J Pharm Sci 2018;5:135-40.

25. Mankala SK, Korla AC, Gade S. Development and evaluation of aceclofenac-loaded mucoadhesive microcapsules. J Adv Pharm Technol Res 2011;2:245-54.

26. Tarun P, Nardev S. Formulation and in vitro evaluation of bilayer tablet of atenolol for biphasic drug release. Asian J Pharm Clin Res 2018;11:114-9.

27. Haritha S, Kotla NG, Balaji M, Sima S, Omprakash S, Kumar A, et al. Formulation and evaluation of atenolol floating bioadhesive system using optimized polymer blends. Int J Pharm Investig 2016;6:116-22.

28. Balagani PK, Chandiran IS, Jayaveera KN. Formulation development and evaluation of glibenclamide loaded Eudragit RLPO microparticles. Int Curr Pharm J 2013;2:196-201.

29. Melike U, Karaman EF. Preliminary studies on solid lipid microparticles of loratadine for the treatment of allergic reactions via the nasal route. Trop J Pharm Res 2013;12:287-93.

30. Shih-Mo Y, Tung-Ming Y, Ming-Huei L, Long H, Cheng-Hsien L.
Moldless PEGDA-based optoelectrofluidic platform for microparticle selection. Adv Optoelectron 2011;2011:1-9.

31. Abhay K, Sonali D, Ghatuary SK, Subhasri M. Design and evaluation of progesterone microparticles using biodegradable polymers. IOSR J Pharm 2013;3:26-8.

32. Josephine LJ, Yathish M, Wilson B, Kumari KB. Formulation and evaluation of microparticles containing curcumin for colorectal cancer. J Drug Deliv Ther 2012;2:125-8.

33. Madan JR, Kadam V, Bandavane S, Dua, K. Formulation and evaluation of microspheres containing ropinirole hydrochloride using biodegradable polymers. Asian J Pharm 2014;7:184-8.

34. Gantala V, Ramanathan S, Mansor SM, Nair NK, Sattar MA, Croft SL, et al. Development and validation of RP-HPLC-UV method for simultaneous determination of buparvaquone, atenolol, propranolol, quinidine and verapamil: A tool for the standardization of rat in situ intestinal permeability studies. J Pharm Biomed Anal 2007;43:1546-51.

35. Natarajan R, Elishaba G, Rangapriya M, Rajendran N. Optimization and evaluation of mucoadhesive microspheres of atenolol. Int $\mathrm{J}$ Res Pharm Chem 2011;1:722-9.

36. Nappinnai M, Kishore VS. Formulation and evaluation of microspheres of diltiazem hydrochloride. Indian J Pharm Sci 2007;69:511-4.

37. Reddy JR, Gnanaprakash K, Badarinath AV, Chetty CM. Formulation and evaluation of microparticles of metronidazole. J Pharm Sci Res 2009; $1: 131-6$

38. Dalu D, Kumar YG. Formulation design and development of gastro retentive floating tablets of atenolol. J Pharm Res 2017;11:479-84.

39. Yagnesh B, Dushyant S. Influence of additives on fabrication and release from protein loaded PLGA microparticles. J Chem Pharm Res 2012;4:1708-15

40. Ahmed N, Hasan I, Saifuddin M, Chowdhury JA, Reza MS. Formulation and optimization of carbamazepine microspheres by 2 factor 2 level central composite design. Bangladesh Pharm J 2016;19:152-60. 